\title{
HIV infection in black Caribbeans in the United Kingdom
}

\section{N Low}

\section{An untold story?}

"...We know that there are black people dying of HIV. But...at a personal level, at an institutional level, at a political level...we've kind of colluded not to tell this story." (Michael Hamilton).'

$\mathrm{T}$ he rate of AIDS among black Caribbeans in the United Kingdom was known to be three times higher than in the majority white population nearly 10 years ago. ${ }^{2}$ The potential for heterosexual spread of HIV within Britain's black Caribbean community is well recognised because of the high risk of gonorrhoea and chlamydia in people from black Caribbean backgrounds ${ }^{3-7}$ and the facilitating effect of bacterial sexually transmitted infections on HIV transmission. ${ }^{8}$ It is, however, the absence of an HIV epidemic that has been remarked upon because of the paradox whereby black Caribbeans have the highest rates of bacterial sexually transmitted infections but black Africans in the United Kingdom bear the highest burden of HIV of any ethnic group with much lower rates of other sexually transmitted infections. ${ }^{9}$ The apparent lack of spread of HIV to black Caribbeans has been attributed to assortative (like with like) sexual mixing within ethnic groups. ${ }^{9}$

The extensive HIV epidemic among Britain's black African communities distracts attention from HIV in black Caribbeans. New HIV diagnoses in black Africans now exceed those in white people, ${ }^{10}$ although black Africans comprise only $0.8 \%$ of the population. ${ }^{11}$ By contrast, there were reassuringly few new HIV diagnoses in black Caribbeans in 2002 (table 1). We need to look at rates of infection, however, to put things in perspective. The rate of newly diagnosed HIV infections is 12 times higher in black Caribbeans than in the white population (table 1 ). This is about the same as the ethnic difference in gonorrhoea rates $^{6}$ that has generated widespread alarm. ${ }^{1}$

The paper in this issue of STI (p 18) by Dougan and colleagues from the Communicable Disease Surveillance Centre is therefore welcome, providing the most detailed information available on the descriptive epidemiology of HIV infections in England, Wales, and Northern Ireland's black Caribbean population. They have shown that there were 691 adults of black Caribbean ethnicity accessing HIV treatment and care services in 2001, two and a half times more than in 1997. Over half of those living with HIV in 2001 acquired their infection heterosexually. About a quarter of male heterosexual, $41 \%$ of female, and $62 \%$ of male homosexual infections were acquired in the United Kingdom.

The analysis of these sources of surveillance data shows that while data about ethnic group have improved since the introduction of ethnic monitoring in the National Health Service in 1994, there are still some limitations. Firstly, ethnic group is still not completed in $14 \%$ of new HIV reports and 6\% of reports on prevalent cases. Although this represents admirable completion for routine data sources, comprehensive interpretation remains difficult because in minority groups where numbers are small the omission of even a few cases will underestimate the proportional contribution of that group. For example, if 50 of the 669 cases in 2001 where ethnic group was not known were from the "black other" group the rate in this group would almost double to 89.2/ 100 000. Secondly, country of birth has been used as a surrogate for ethnic group in the unlinked anonymous prevalence surveys. Aside from issues about involved in the programme, country of birth alone is of no use for determining the distribution of HIV in Britain's black populations because $58 \%$ of black Caribbeans and 33\% of black Africans were born in the United Kingdom. ${ }^{11}$ This paper gives a further signal that it is time to record ethnic group in the unlinked anonymous prevalence surveys and to introduce person based sexually transmitted infection surveillance recording ethnic group across the United Kingdom now. The new ethnic group classification of the 2001 census should be used because it takes those describing themselves as black British or of mixed ethnic origin out of the "black other" category. This will allow a better understanding of the epidemiology of sexually transmitted infections and HIV in those previously classified as "black other," who have appeared to be at even higher risk than people describing themselves as black Caribbean (table 1$){ }^{6}$

Do these data indicate a new epidemic? Yes and no. The incidence of HIV in black Caribbeans is clearly disproportionate relative to the size of the population and the number of cases is increasing. In comparison with the United States, however, the scale of the problem in British African Caribbeans is small. African Americans (who are also primarily of Caribbean descent) accounted for $49 \%(n=7023)$ of AIDS cases in the United States in $2001,{ }^{12}$ compared with $29 \%(\mathrm{n}=9978)$ in 1989. Part of the explanation for this may be that injection drug use accounts for about $20 \%$ of new HIV infections in African Americans ${ }^{12}$ but very few in black Caribbeans in the United Kingdom (Dougan and colleagues, p 18). The UK surveillance data and trends cannot tell us for sure whether HIV in black Caribbeans will remain under control or whether this is the start of a rapid rise in transmission. Dougan and colleagues analysed data up to the end of 2001. The most recent figures show that new HIV diagnoses increased by another 13\% in black Caribbeans and

Table 1 Rates of newly diagnosed HIV infection, United Kingdom, 2002

\begin{tabular}{|c|c|c|c|c|}
\hline Ethnic group & Population & New HIV diagnoses & Rate per 100000 & Rate ratio $(95 \% \mathrm{Cl})$ \\
\hline White & 54153898 & 1667 & 3.1 & 1 (reference) \\
\hline Black Caribbean & 565876 & 214 & 37.8 & $12.3(10.6$ to 14.2$)$ \\
\hline Black African & 485277 & 2610 & 537.8 & $174.7(164.2$ to 185.9$)$ \\
\hline Black other & 97585 & 46 & 47.1 & $15.3(11.2$ to 20.5$)$ \\
\hline $\begin{array}{l}\text { Indian/Pakistani/ } \\
\text { Bangladeshi/other } \\
\text { Asian/Chinese }\end{array}$ & 2578826 & 40 & 1.6 & $0.5(0.4$ to 0.7$)$ \\
\hline Other/mixed & 907732 & 150 & 16.5 & $5.4(4.5$ to 6.3$)$ \\
\hline Not known & - & 984 & - & - \\
\hline
\end{tabular}

Source: Health Protection Agency and the Scottish Centre for Infection and Environmental Health ${ }^{10}$ and Table S102, 2001 Census.

Ethnic groupings are those used by the Communicable Disease Surveillance Centre. 


\section{EDITORIAL}

$23 \%$ in black Africans between 2001 and $2002 .{ }^{10}$

The time has come to develop high profile primary HIV prevention with Britain's black Caribbean population. As the quotation at the beginning of this editorial acknowledges there has been a reluctance at all levels to "tell this story." The fear of perpetuating racist stereotypes undoubtedly contributes to the paucity of sexual health research among ethnic minorities. ${ }^{213}$ We need to know more about how ethnic patterns of sexual mixing change over time and how they affect the spread of sexually transmitted infections in European countries whose demographic structures differ from the United States. Misplaced political correctness may also inhibit the implementation of interventions aimed at behaviour change lest they be viewed as culturally insensitive. ${ }^{14}$ The challenge is to get across the message that the rates of HIV among black Caribbeans are currently modest but that persistently high gonorrhoea rates are providing fuel for an explosive epidemic. The issue of HIV must first be taken on by black Caribbean communities so that partnerships for research and prevention can find out what works. Anecdotally, this is already happening. As one young black woman puts it, "Now we know[,]...everything negative is owned by black people. We need to come together as a community and do something about it."

Sex Transm Infect 2004;80:2-3.

doi: $10.1136 /$ sti.2003.007138

Correspondence to: $\mathrm{N}$ Low, Department of Social Medicine, University of Bristol, Canynge Hall, Whiteladies Road, Bristol BS8 2PR, UK. nicola.low@bristol.ac.uk

\section{REFERENCES}

1 Geoghegan B. STD in Afro-Caribbean community. BBC Newsnight, 24 July 2003. Accessed 23 October 2003. (news.bbc.co.uk/1/ hi/programmes/newsnight/3092611.stm)

2 De Cock KM, Low N. HIV and AIDS, other sexually transmitted diseases and tuberculosis in ethnic minorities in the United Kingdom: is surveillance serving its purpose? BMJ 1997:314:1747-51.

3 Hickman M, Judd A, Maguire $H$, et al. Incidence of gonorrhoea diagnosed in GUM clinics in South Thames (West) Region. Sex Transm Infect 1999:75:306-11.

4 Lacey CJN, Merrick DW, Bensley DC, et al. Analysis of the sociodemography of gonorrhoea in Leeds, 1989-93. BMJ 1997:314:1715-18.
5 Low N, Daker-White G, Barlow D, et al. Gonorrhoea in inner London: results of a cross sectional study. BMJ 1997;314:1719-23.

6 Low N, Sterne JA, Barlow D. Inequalities in rates of gonorrhoea and chlamydia between black ethnic groups in south east London: cross sectiona study. Sex Transm Infect 2001;77:15-20.

7 Shahmanesh M, Gayed S, Ashcroft M, et al. Geomapping of chlamydia and gonorrhoea in Birmingham. Sex Transm Infect 2000;76:268-72.

8 Wasserheit JN. Epidemiological synergy: interrelationships between human immunodeficiency virus infection and other sexually transmitted diseases. Sex Transm Dis 1992;19:61-77.

9 Barlow D, Daker-White G, Band B. Assortative sexual mixing in a heterosexual clinic population-a limiting factor in HIV spread? AIDS 1997; 11:1041-6.

10 HPA and SCIEH. AIDS/HIV Quarterly Surveillance Tables. UK Data to End March 2003. London. Health Protection Agency and the Scottish Centre for Infection \& Environmental Health. 2003;58:03/03, Table 12b.

11 Office for National Statistics. The 2001 census Table S102: Sex and country of birth by ethnic group. London: Office for National Statistics, 2003. (www.statistics.gov.uk/STATBASE/ Expodata/Spreadsheets/D6832.xls)

12 Centers for Disease Control and Prevention HIV/AIDS surveillance report. Atlanta: Centers for Disease Control and Prevention, 2001; 13(No 2): 1

13 Fenton KA. Strategies for improving sexual health in ethnic minorities. Curr Opin Infect Dis 2001; 14:63-9.

14 Bayer R. AIDS prevention and cultural sensitivity: are they compatible? Am J Public Health 1994;84:895-8.

\section{$\mathrm{ECHO}$}

New instrument has been developed to measure quality of care for HIV patients

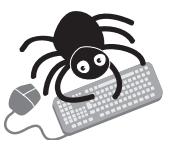

Please visit the Sexually Transmitted Infections website [www. stiijournal.com] for a link to the full text of this article. n HIV specific version of the QUOTE (quality of care through the patient's eyes) $\triangle$ questionnaire is a useful instrument for measuring the quality of care of HIV infected patients.

The questionnaire differs from traditional patient satisfaction questionnaires in several ways. It offers an importance as well as a performance component, so the importance component can be added as a weight factor in the judgment of quality of care. Patients played a crucial part in the development of this instrument. As a result an equal number of items encountered specifically by HIV infected patients as well as known patients' satisfaction items were generated.

Focus group discussions were held to select aspects for inclusion in the questionnaire, and 13 generic and 14 HIV specific items were included as a result. Item and interitem analysis, factor analysis, and reliability analysis were performed to test internal consistency and validity of the instrument.

The questionnaire was sent to 80 people infected with HIV, and 44 questionnaires were returned. One striking finding was a need for an education course for general practitioners, in which more attention is paid to the use of HIV medication. Further research is, however, needed for specific groups of patients.

A Quality and Safety in Health Care 2003;12:188-193. 